\title{
Um perfil de Nelson Chaves e da sua contribuição à nutrição em saúde pública no Brasil
}

\author{
A biographical profile of Nelson Chaves \\ and his contribution to nutrition in public \\ health in Brazil
}

Francisco de Assis Guedes de Vasconcelos 1

\footnotetext{
1 Departamento de Nutrição, Centro de Ciências da Saúde, Universidade Federal de Santa Catarina.

Campus Universitário Trindade, Florianópolis, SC 88040-900, Brasil.
}

Abstract This study focuses on the academic and intellectual career of scientist Nel son Chaves, founder of the Nutritionists School and the Institute of Nutrition at the Federal University in Pernambuco. The methodol ogy was based on quantitative and qualitative analyses of this author's scientific production, published from 1932 to 1982. Beginning with his search for solutions to malnutrition children from the Zona da Mata region in Pernambuco, this scientist created what is commonly called the humanist-ecological paradigm of the Brazilian nutritional issue, thus contributing to the institutionalization of the field of nutrition in public heal th throughout Brazil.

Key words Nutrition; Infant Nutrition; Literature

Resumo O objetivo deste trabalho foi investigar a trajetória acadêmi co-intel ectual do cientista Nelson Chaves, fundador do Curso de Nutricionistas e do Instituto de Nutrição da Universi dade Federal de Pernambuco. A metodologia utilizada baseou-se em uma análise quanti-qualitativa da produção científica deste autor, publicada no período de 1932 a 1982. Os resultados do estudo procuram demonstrar que, val endo-se das suas preocupações em buscar soluções para a problemática da desnutrição infantil na Zona da Mata pernambucana, este ci entista construiu o que chamamos de paradigma ecológi co-humanista da questão nutricional brasileira, contribuindo para a institucionalização do campo da nutrição em saúde pública em todo território naci onal. Palavras-chave Nutrição; Nutrição Infantil; Literatura 


\section{Introdução}

Diferentes abordagens têm sido realizadas sobre a emergência da nutrição em saúde pública, também reconhecida por nutrição em medicina preventiva (Shank, 1976), nutrição social, nutrição comunitária ou, ainda, nutrição em saúde coletiva (Vasconcelos, 1990; Ypiranga \& Gil, 1989), enquanto um dos campos ou áreas de estudo específicos da complexa e multidisciplinar ciência da nutrição.

De acordo com alguns estudos, foi a partir dos anos 1960, sobretudo no decorrer da I Conferência sobre adestramento de nutricionistasdietistas de saúde pública, realizada em 1966, em Caracas, Venezuela, que se passou a discutir, na comunidade latino-americana de nutrição, a formação de "um profissional denível universitário, qualificado por formação eexperiência, para atuar nos serviços de saúde pública com o fim de melhorar a nutrição humana, essencial para a manutenção do mais al to nível de saúde" (Boletim da Associação Brasileira de Nutricionistas, 1966, apud Ypiranga \& Gil, 1989:25).

Outros estudos, entretanto, apontam que a gênese deste campo específico da nutrição, dentro do cenário internacional, teria ocorrido no interior de agências especializadas da Organização das Nações Unidas (ONU), tais como o United Nations International Children Emergency Fund (UNICEF), a Food and Agriculture Organization (FAO), a Organização Mundial de Saúde (OMS) e a Organização Pan-Americana de Saúde (OPAS). Agências criadas, a partir de 1946, com o intuito de administração dos conflitos da nova ordem político-econômica mundial, estabelecida no pós-2a Guerra, quando teve início a chamada guerra fria entre os países capitalistas, liderados pelos Estados Unidos da América, e os países socialistas, liderados pela então União das Repúblicas Socialistas Soviéticas (Coimbra et al., 1982; L'Abbate, 1982; Vasconcelos, 1999b).

Pelas análises dos autores investigados, depreendemos que a preocupação com a questão da alimentação e nutrição da população mundial (dentro de uma abordagem do coletivo) teve início com o desenrolar da 2a Guerra mundial. Um primeiro indício desta preocupação foi a realização, em 1941, da National Nutrition Conferencefor Defense (conhecida como a Conferência de Washington), convocada pelo presidente Roosevelt. O passo seguinte foi a realização, em 1943, da Conferência de Alimentação de Hot Spring, Virgínia, também convocada por aquele presidente norte-americano, com a participação de representantes de 44 países, quando foi proposta a criação de um órgão in- ternacional especializado em alimentação. Esta conferência de 1943 deu origem à criação, em 1946, tanto da FAO, entidade da ONU responsável pela questão da alimentação e nutrição mundial, como do UNICEF, inicialmente uma entidade com fins humanitários de assistência às crianças européias vítimas dos efeitos da Segunda Guerra Mundial. E em 1948, em Montevidéu, no Uruguai, realizou-se a la Conferência Latino-Americana da FAO, sendo este o primeiro evento científico desta agência a recomendar o desenvolvimento de atividades específicas no campo da nutrição em saúde pública, dentro do contexto internacional (Castro, 1980; Coimbra et al., 1982; L'Abbate, 1982; Vasconcelos, 1999b).

No caso do Brasil, a emergência do processo de institucionalização do campo da nutrição em saúde pública tem sido associada à fundação, em 1957, do Curso de Nutricionistas do então Instituto de Fisiologia e Nutrição da Faculdade de Medicina de Recife (atual Curso de Graduação em Nutrição do Departamento de Nutrição da Universidade Federal de Pernambuco - UFPE), apontado como o primeiro curso brasileiro a formar profissionais voltados para atuação neste campo específico (Coêlho, 1983). Processo este que teve como um dos seus protagonistas o médico Nelson Ferreira de Castro Chaves (1906-1982). Com base nesta premissa, o presente estudo se propõe a examinar a trajetória acadêmico-intelectual deste cientista pernambucano, procurando apontar a sua contribuição ao processo de gênese e consolidação da nutrição em saúde pública no Brasil. A investigação teve um eixo longitudinal de análise iniciado em 1932, ano da sua primeira publicação científica, e concluído em 1982, ano da sua morte. A este eixo longitudinal, sobrepõem-se quatro cortes transversais (1932/ 1945, 1946/ 1963, 1964/ 1972 e 1974/ 1982), correspondentes a contextos específicos da trajetória investigada, por nós estabelecidos como critérios metodológicos de análise.

\section{Metodologia}

Nossa análise da trajetória intelectual de Chaves, ao longo do período 1932-1982, teve como base empírica inicial a publicação Memória Científica do Departamento de Nutrição e das Instituições Predecessoras (1950-1995) (Costa, 1995b). Esta publicação, como o próprio título sugere, constitui um precioso registro histórico sistemático da produção científica dos docentes vinculados ao atual Departamento de Nutrição da UFPE, contendo listas anuais dos tí- 
tulos publicados, dentro de um eixo longitudinal que se inicia em 1932, ano da primeira publicação científica de Chaves, e avança até outubro de 1995, ano da comemoração dos quarenta anos de fundação da referida instituição. Destacamos, todavia, que apesar da grande contribuição que este trabalho nos prestou, uma vez que nos poupou de um exaustivo levantamento bibliográfico sobre a produção científica deste autor, não nos eximiu da realização de um levantamento paralelo. Ao realizar tal levantamento, identificamos algumas poucas imprecisões do referido registro, as quais apontamos ao longo de nossa análise e que, a nosso ver, não abalam a sua representatividade, particularmente para o tipo de estudo que realizamos.

Fundamentados no mapeamento registrado por Costa (1995b), o primeiro procedimento metodológico que desenvolvemos para analisar a trajetória da produção científica deste cientista foi o estabelecimento de critérios de sistematização que nos possibilitasse traçar um perfil quanti-qualitativo de sua obra. Sendo assim, dentro dos quatro cortes transversais que compõem o eixo longitudinal investigado (1932/ 1945, 1946/ 1963, 1964/ 1972 e 1973/ 1982), apresentamos uma análise quanti-qualitativa da produção científica de Chaves, baseada nos critérios bibliométricos estabelecidos. Ou seja, em um primeiro momento, cada título deste cientista foi submetido a uma análise quantitativa e de categorização, em relação aos critérios de autoria, natureza e temática abordada. Quanto ao critério de autoria, os títulos publicados foram quantificados e categorizados em autoria individual; autoria coletiva ou grupal (dois ou mais autores); autoria principal (primeiro nome listado) e autoria secundária ou coadjuvante (todos da lista, exceto o autor principal). Quanto ao critério de natureza do título, estes foram quantificados e categorizados de acordo com as suas respectivas modalidades de publicação: livro; capítulo de livro; tese; dissertação; monografia; artigo de periódico especializado internacional, nacional, local ou institucional; artigo de periódico não especializado (jornais); artigo ou resumo de anais de eventos científicos e outras modalidades. $\mathrm{E}$ quanto ao critério das temáticas abordadas, os títulos foram quantificados e categorizados dentro de três campos temáticos gerais, tais como nutrição em saúde pública, nutrição básica e experimental e nutrição clínica (incluindo endocrinologia, fisiologia, patologia e dietoterapia), bem como dentro de campos temáticos específicos, oriundos do desdobramento destes campos temáticos gerais.
Em cada corte transversal investigado, após a apresentação do perfil quanti-qualitativo dos títulos publicados naquele período, a análise da sua produção científica é complementada com o estudo de um ou mais destes títulos. A rigor, a adoção deste procedimento metodológico deu-se em função da necessidade de identificação e aprofundamento das possíveis especificidades, semelhanças e diferenças de natureza teórico-conceitual existentes ao longo da trajetória acadêmico-intelectual deste cientista. Em geral, os critérios de seleção dos títulos analisados foram estabelecidos em função das características do perfil quanti-qualitativo da sua produção científica de cada período e, em alguns casos, o critério se deu em função da facilidade de acesso à respectiva publicação.

\section{2/1945: da clínica terapêutica à fisiologia da nutrição}

Nelson Chaves nasceu no dia 08 de junho de 1906, no Engenho Vênus, Município de Água Preta, localizado na Zona da Mata-Sul, Pernambuco, onde viveu sua infância e adolescência. Em 1930, aos 24 anos de idade, diplomouse médico pela Faculdade Nacional de Medicina do Rio de Janeiro. Em 1931, retornando à cidade do Recife, foi convidado pelo professor Fernando Simões Barbosa para ser seu assistente no Hospital do Centenário. Em 1932, em sua clínica particular, começou o exercício da profissão desenvolvendo atividades médicas na especialização de endocrinologia e nutrição. Em 1934, ingressou na Faculdade de Medicina da Universidade do Recife como professor assistente da cátedra de clínica terapêutica, consagrando-se livre-docente desta mesma cátedra, em 1935. Em 1941, abdicou de sua clínica particular para dedicar-se exclusivamente à carreira universitária. No período de 1940 a 1943, época do governo de Agamenon MagaIhães, exerceu o cargo de diretor geral do Departamento de Saúde Pública de Pernambuco, dando início a sua atuação na gestão de instituições públicas estaduais. Finalmente, em 1943, consagrou-se titular da cátedra de fisiologia, com a defesa da tese As Adrenais na Fisiologia Sexual (Andrade, 1991; Coêlho, 1983; Costa, 1995a; Kelner et al., 1985).

A trajetória intelectual de Chaves, conforme registrada por Costa (1995b), teve início no ano de 1932, com a publicação de seus três primeiros artigos científicos (três estudos de casos clínicos sobre cretinismo endêmico, hipertireoidismo e artrite pulmonar) em periódicos editados em Recife, Pernambuco. No mapea- 
mento de sua produção científica, no período de 1932 a 1945, foram registrados 25 títulos de sua autoria.

De acordo com os critérios de sistematização que utilizamos para traçar um perfil de sua obra, podemos dizer que quanto à autoria (Tabelas 1 e 2), 23 títulos são de autoria individual e nos dois demais, ele também aparece como o autor principal.

Quanto à natureza do título (Tabela 3), 18 são artigos publicados em periódicos locais; dois são livros; três são artigos publicados em jornais locais; um é publicação em anais de evento científico e um é sua tese de professor catedrático em fisiologia. Portanto, a principal modalidade de publicação do período foi o artigo em periódico especializado editado em Recife, notadamente na Revista de Medicina de Pernambuco e Neurobiologia, representando $72,0 \%$ do total de títulos. A primeira publicação em formato de livro data de 1935, tendo como título Tratamento Médico do Hipertireoi dismo. O primeiro artigo publicado em jornal local data de 1937 e também aborda aspectos do cam-

Tabela 1

Distribuição dos títulos publicados por Nelson Chaves segundo períodos investigados e categorias de autoria (individual e coletiva), 1932-1982.

\begin{tabular}{lccc}
\hline Período & Individual & Coletiva & Total \\
\hline $1932 / 1945$ & 23 & 2 & 25 \\
$1946 / 1963$ & 55 & 31 & 86 \\
$1964 / 1972$ & 75 & 12 & 87 \\
$1973 / 1982$ & 42 & 14 & 56 \\
Total & 190 & 64 & 254 \\
$\%$ & 74,8 & 25,2 & 100,0 \\
\hline
\end{tabular}

Tabela 2

Distribuição dos títulos publicados por Nelson Chaves segundo períodos investigados e categorias de autoria (principal e secundária), 1932-1982.

\begin{tabular}{lccc}
\hline Período & Principal & Secundária & Total \\
\hline $1932 / 1945$ & 25 & 0 & 25 \\
$1946 / 1963$ & 81 & 5 & 86 \\
$1964 / 1972$ & 78 & 9 & 87 \\
$1973 / 1982$ & 45 & 11 & 56 \\
Total & 229 & 25 & 254 \\
$\%$ & 90,2 & 9,8 & 100,0 \\
\hline
\end{tabular}

po da endocrinologia. Enquanto o segundo, data de 1944, tem como título A Proteína na Al imentação do Povo, prenunciando a ampliação dos campos temáticos que a obra de Chaves tomaria nas décadas seguintes.

Quanto às temáticas abordadas (Tabela 4), $23(92,0 \%)$ foram inseridos no campo da endocrinologia e/ ou fisiologia e $2(8,0 \%)$ no campo da nutrição em saúde pública. Portanto, observou-se que, entre 1932 a 1944, as publicações deste cientista foram inseridas dentro da perspectiva biológica, exclusivamente no campo da endocrinologia e/ ou fisiologia, e tiveram como temáticas específicas o hipertireoidismo, o diabete insípido, a hipoglicemia espontânea, outras alterações endócrinas e a fisiologia sexual.

Ou seja, esta primeira fase da trajetória intelectual de Chaves, compreendida entre os seus 24 a 39 anos de idade, caracterizou-se pela sua dedicação exclusiva à clínica terapêutica, especialmente ao estudo de casos clínicos, enfocando aspectos fisiológicos e endocrinológicos individuais. Ao final deste primeiro corte transversal investigado, que englobou todo o transcurso do chamado Estado Novo ou Ditadura Vargas (1937-1945), as duas primeiras publicações com uma abordagem dentro da perspectiva social anunciavam os novos rumos da sua trajetória acadêmico-intelectual, em direção às pesquisas laboratoriais no campo da nutrição experimental e às pesquisas populacionais no campo da nutrição em saúde pública. A origem de tais alterações, embora não tenham sido suficientemente exploradas, devem ser buscadas e compreendidas dentro do contexto de redemocratização da sociedade brasileira do pós-1945, bem como na sua própria atuação como diretor geral do Departamento de Saúde Pública de Pernambuco, cargo que propiciou e/ ou exigiu uma ampliação dos campos de conhecimento e atuação deste cientista, para além das fronteiras da dimensão exclusivamente biológica, característica da fisiologia e da endocrinologia. Além disso, algumas das raras referências sobre as suas atividades político-partidárias apontam que ele teria participado, em 1945, com o médico nutrólogo Dante Costa e outros intelectuais, do processo de formação da Esquerda Democrática, base para a criação do Partido Socialista Brasileiro (PSB) (Coimbra et al., 1982; Costa, 1954). Entretanto, acreditamos que estes aspectos precisam ser melhor aprofundados. 
Distribuição dos títulos publicados por Nelson Chaves segundo tipo de publicação por períodos investigados, 1932-1982.

\begin{tabular}{lccccc}
\hline Tipo de publicação & $1932 / 1945$ & $1946 / 1963$ & $1964 / 1972$ & $1973 / 1982$ & Total \\
\hline Periódicos & & & & & \\
$\quad$ Internacional & 0 & 6 & 16 & 14 & 13 \\
$\quad$ Nacional & 0 & 39 & 4 & 2 & 69 \\
$\quad$ Local & 18 & 2 & 6 & 3 & 21 \\
Livro & 2 & 10 & 1 & 17 & 19 \\
Capítulo de Livro & 0 & 1 & 7 & 13 & 26 \\
Evento (Anais) & 1 & 5 & 4 & 2 & 10 \\
Publicações da Universidade & 1 & 3 & 45 & 2 & 70 \\
Federal de Pernambuco & 3 & 20 & 87 & 56 & 254 \\
Jornal & 25 & 86 & & & \\
Total & & &
\end{tabular}

Tabela 4

Distribuição dos títulos publicados por Nelson Chaves segundo área temática por períodos investigados, 1932-1982.

\begin{tabular}{|c|c|c|c|c|c|c|c|c|c|c|}
\hline \multirow[t]{2}{*}{ Área temática } & \multicolumn{2}{|c|}{$1932 / 1945$} & \multicolumn{2}{|c|}{$1946 / 1963$} & \multicolumn{2}{|c|}{$1964 / 1972$} & \multicolumn{2}{|c|}{$1973 / 1982$} & \multicolumn{2}{|c|}{ Total } \\
\hline & $\mathrm{n}$ & $\%$ & $\mathrm{n}$ & $\%$ & $\mathrm{n}$ & $\%$ & $\mathrm{n}$ & $\%$ & $\mathrm{n}$ & $\%$ \\
\hline Fisiologia/endocrinologia & 23 & 92,0 & 30 & 34,9 & 13 & 14,9 & 28 & 50,0 & 94 & 37,0 \\
\hline Nutrição básica e experimental & 0 & 0,0 & 24 & 27,9 & 12 & 13,8 & 8 & 14,3 & 44 & 17,3 \\
\hline Nutrição em saúde pública & 2 & 8,0 & 32 & 37,2 & 62 & 71,3 & 20 & 35,7 & 116 & 45,7 \\
\hline Total & 25 & 100,0 & 86 & 100,0 & 87 & 100,0 & 56 & 100,0 & 254 & 100,0 \\
\hline
\end{tabular}

1946/1963: do laboratório de nutrição experimental aos estudos populacionais

Perseguindo a trajetória acadêmico-intelectual de Chaves, importantes acontecimentos do contexto 1946-1963 merecem ser destacados. O primeiro diz respeito a sua atuação, no período de 1949-1951, como secretário de saúde e assistência social do Estado de Pernambuco, por ocasião do governo de Barbosa Lima Sobrinho. Ao final deste período, ele encerrou definitivamente sua rápida passagem pela administração de agências públicas do governo estadual, dedicando-se exclusivamente à academia, sobretudo, às atividades de ensino, pesquisa e extensão no campo da nutrição. Assim sendo, ainda em 1950, criou o Instituto Álvaro Ozório de Almeida, cuja finalidade inicial foi "reunir as cátedras de fi si ol ogia, histologia, embriologia geral e técnica operatória da Faculdade de Medicina da Universi dade do Recife, bem como a realização de pesquisa científica, em especial sobreas condi ções fisiológi cas do homem das regi ões tropicais" (Costa, 1995a: 24). Em março de 1956, o referido instituto passou a denominar-se Instituto de Fisiologia e Nutrição e, em 1962, Instituto de Nutrição da UFPE (INUFPE). Destacamos ainda, a criação, em 1957, do Curso de Nutricionistas; a realização, em 1963, da pesquisa nutricional conhecida como Northeast Brazil Nutrition Survey, patrocinada pelo Interdepartmental Committee on Nutrition for National Development (ICNND) dos Estados Unidos e, neste mesmo ano, o início dos Cursos de Especialização em Nutrição em Saúde Pública para médicos, patrocinados pela OPAS, todos sob a direção deste cientista (Coêlho, 1983; Costa, 1995a).

No mapeamento da trajetória intelectual de Chaves, no período de 1946 a 1963, foram listados 86 títulos de sua autoria, o que representa $72,9 \%$ do total de 118 títulos arrolados em Costa (1995b), denotando o peso deste cientista no conjunto das publicações desta instituição específica. 
Quanto ao critério autoria (Tabelas 1 e 2), 55 títulos são de autoria individual e 31 de autoria coletiva, sendo que em 26 destes o professor aparece como o autor principal. Ressaltando-se que, neste período, ele teve como principal parceira a professora Naíde Regueira Teodósio, com a qual dividiu a publicação de 19 títulos.

Quanto ao critério natureza da publicação (Tabela 3), seis são artigos publicados em periódicos internacionais; 39 são artigos publicados em periódicos nacionais; dois são artigos publicados em periódicos locais; 10 são livros; um é capítulo de livro; vinte são artigos publicados em jornais locais; cinco são publicações em anais de eventos científicos e três são publicações editadas pela UFPE. Logo, ressaltamos que a principal modalidade de publicação do período passou a ser o artigo em periódico nacional, representando $45 \%$ dos títulos publicados e que, em 1952, foi publicado seu primeiro artigo em periódico latino-americano, iniciando sua projeção no cenário internacional. Os periódicos de circulação de tais artigos foram, quase que exclusivamente, Revista Brasileira de Medicina e Ciência eCultura, e apenas um destes artigos foi publicado nos Arquivos Brasi leiros de Nutrição - periódico editado por Josué de Castro e seus pares do então Instituto de Nutrição da Universidade do Brasil (Vasconcelos, 1999a).

Quanto ao critério temáticas abordadas (Tabela 4), 30 (34,9\%) foram inseridos nos campos da fisiologia e/ ou endocrinologia; 32 (37,2\%), no campo da nutrição em saúde pública e/ ou tema de conteúdo social; e 24 (27,9\%), no campo da nutrição básica e experimental. O primeiro título em que aparece uma abordagem social da questão nutricional nordestina data de 1946, coincidentemente, ano da primeira edição do clássico de Castro, Geografia da Fome (Castro, 1980). Em 1947 foram publicados os dois primeiros artigos em periódico nacional, ambos descrevendo as condições de subalimentação no Nordeste brasileiro. Portanto, indícios tanto da projeção nacional como da mudança de rumo ou da ampliação de novas fronteiras que a trajetória intelectual de Chaves engendraria. Em 1948 foi publicada sua primeira produção no campo da nutrição básica e experimental, abordando a questão do uso da Mucunã vermelha (Dioclea grandiflora Benth) na nutrição humana. Produção esta que, além deste significado apontado, representa ainda a sua primeira publicação coletiva tendo a participação de alguns dos principais parceiros de sua trajetória intelectual nos anos 1950/ 1960, tais como a médica Naíde Regueira
Teodósio e o químico Oswaldo Gonçalves Lima. Além disso, representa a peça fundamental para a explicitação das divergências político-ideológico-intelectuais entre Chaves e Castro, a partir de então (Vasconcelos, 1999b).

Analisando o conjunto das publicações do período 1946/1963, observamos que o tema central que caracterizou a obra deste autor nestes anos foi a questão do valor biológico das proteínas na alimentação humana nas regiões tropicais. Assim, identificamos que pelo menos 33 (38,4\%) dos 86 títulos editados neste período versam sobre este objeto de investigação. No período em foco, esta temática surge com os primeiros resultados dos estudos experimentais sobre o valor biológico das proteínas do feijão mulatinho (Phaseolus vulgaris), considerada a leguminosa mais usada na alimentação do nordestino, constituindo não apenas uma das suas bases energéticas, mas uma importante base protéica. A partir de então, os pesquisadores do INUFPE, liderados por Chaves, ampliaram consideravelmente suas investigações acerca do valor biológico e outras propriedades das proteínas do feijão mulatinho e de outras espécies vegetais, acenando para o início dos estudos sobre as misturas protéicas vegetais (modalidade de pesquisa que predominaria na investigação científica em nutrição nos anos 1964/ 1972).

Por outro lado, a análise do conjunto das publicações deste período também nos faz observar uma nítida continuidade das temáticas da perspectiva biológica - particularmente dos campos da endocrinologia e da fisiologia - e, simultaneamente, a emergência das temáticas vinculadas à perspectiva social. A leitura de determinados títulos que categorizamos dentro da perspectiva biológica, a exemplo de A Emoção ea Vida Moderna (Chaves, 1957a, 1957b) e Arterosclerose e Nutrição (Chaves, 1959a, 1959b), nos faz identificar o grande esforço de Chaves em procurar construir um campo da nutrição em Pernambuco, atualizado e conectado às modernas discussões científicas travadas nos países do primeiro mundo; contudo, alienado das discussões políticas sobre a realidade de fome e miséria da população nordestina, travadas naquela conjuntura (a exemplo da realização do Congresso de Salvação do Nordeste, em 1955; da efervescência do movimento das Ligas Camponesas no período 1955/ 1964; da atuação da delegacia regional da Associação Mundial de Luta Contra a Fome (ASCOFAM), no período de 1958/ 1964, e da atuação da Superintendência do Desenvolvimento do Nordeste (SUDENE), sob a presidência do economista Celso Furtado, no período de 1960/1964) 
(Azevêdo, 1982; Furtado, 1997; Soares, 1982; Vasconcelos, 1999b). Nestes textos, apesar da abordagem essencialmente vinculada aos campos da fisiologia e endocrinologia, ele introduz importantes conteúdos vinculados à epidemiologia nutricional das chamadas doenças crônico-degenerativas, associadas ao consumo inadequado e/ ou em excesso de nutrientes. Acrescente-se que, ao conceber estes distúrbios nutricionais como produtos da modernidade, das inovações tecnológicas, do sedentarismo, da destituição de valores éticos e morais da humanidade, etc., ele introduz determinados elementos do chamado humanismo cristão que, em certa medida, caracterizaria suas publicações nos anos subseqüentes.

$\mathrm{Na}$ verdade, retomando a trajetória acadêmico-intelectual deste autor, notamos que foi no contexto anteriormente analisado que esta sua perspectiva humanista despontou, em especial no discurso proferido ao tomar posse na cadeira de fisiologia da Faculdade de Medicina da Universidade do Recife, em 21 de agosto de 1943, publicado em 1949, sob a forma do artigo Conceitos em Torno do Ensino da Fisiologia (Chaves, 1949, apud Monteiro, 1995) e, em seguida, no pequeno ensaio A Ciência no Mundo Contemporâneo, produzido em 1947 (Chaves, 1947, apud Lago, 1995). Entretanto, conforme sinalizamos anteriormente, será a partir dos anos 1960 que esta perspectiva ganhará maior consistência em sua obra. Ao realizar uma curta autobiografia em Sexo, Nutrição eVida, Chaves (1968) refere que os autores de sua predileção são os espanhóis Miguel de Unamuno, José Ortega y Gasset e Gregório Marañon. Explicita ainda que foi o médico fisiologista Gregório Marañon, quem marcou a sua orientação humanista. Além destes, ao discutir os três temas complexos e polêmicos que intitulam este seu livro, ele procura dialogar com um leque bastante ampliado de autores, tais como Albert Einstein, Aldous Huxley, George Bernard Shaw, Kalil Gibran, Louis Joseph Lebret, Luís de Camões e Sigmund Freud. Os quais, incluindo os seus três autores prediletos, a nosso ver, caracterizam ou constituem diferentes matizes da perspectiva humanista construída por Chaves ao longo de sua trajetória acadêmico-intelectual, na qual, conforme aponta Batista Filho (1995:78), “o interesse central pel o homem eo respeito primordial pela natureza, tornaram-se pól os dominantes de suas preocupações de cientista e pensador".
1964/1972: o tratamento

e a recuperação da desnutrição infantil na Zona da Mata pernambucana

Em 1964, com a criação da Divisão de Nutrição em Saúde Pública do INUFPE, foi constituído o núcleo inicial de docentes responsáveis pelo desenvolvimento de um conjunto de ações específicas, como a realização de pesquisas nutricionais na Zona da M ata pernambucana, a implantação dos Centros de Educação e Recuperação Nutricional (CERNs) e a elaboração de Planos de Ações de Nutrição a serem desenvolvidos pelas Secretarias Estaduais de Saúde, características do processo de institucionalização do campo da nutrição em saúde pública protagonizado por Chaves. Outros fatos verificados no período 1964/ 1972 merecem ser destacados: em 1970, Chaves fundou o Curso de Mestrado em Nutrição do INUFPE, cujo início efetivo ocorreu em abril de 1971, tendo como objetivos "preparar pessoal dealto nível para atender à demanda de profissionais de nutrição nos setores de docência, de pesquisa e de assessoria, supervisão e planejamento de serviços de saúde pública" (Costa, 1995a: 219); ocupou no ano de 1971, o cargo de pró-reitor de pesquisa e pós-graduação da UFPE (Coêlho, 1983; Costa, 1995a).

No levantamento de sua produção científica, observamos que, no período de 1964/ 1972, foram listados 87 títulos de sua autoria, o que representa $47,0 \%$ do total de 185 títulos arrolados em Costa (1995b). Verificamos ainda que, apesar da redução percentual do número de títulos publicados por Chaves em relação aos títulos totais da instituição (decorrente da ampliação do quadro de pesquisadores do INUFPE), quantitativamente este foi o período de maior atividade produtiva do autor, além de o mesmo permanecer sendo o primeiro do grupo em termos de títulos publicados. Além disso, em nosso levantamento paralelo, identificamos a publicação de um livro que não consta na relação de Costa (1995b), e que é de Chaves (1968).

Quanto ao critério autoria (Tabelas 1 e 2), 75 são de autoria individual e 12 de autoria grupal.

Quanto ao critério natureza do título ( Tabela 3), identificamos quatro artigos publicados em periódicos internacionais; 16 em periódicos nacionais e quatro em periódicos locais e do INUFPE; 45 artigos em jornais não especializados (em sua ampla maioria locais - Diário dePernambuco e Jornal do Commércio -, entretanto, também no Jornal do Brasil e Fol ha de São Paulo); sete publicações em anais de eventos científicos; quatro relatórios técnicos de projetos de pesquisa/ intervenção nutricional; 
seis livros (e monografias) e um capítulo de livro. Portanto, a principal modalidade de publicação do período foi o artigo de jornal, que representou cerca de $51,7 \%$ do total de títulos, seguido do artigo publicado em periódico especializado (internacional e nacional) que representou cerca de $22,9 \%$ do total. A Revista Brasileira de Medicina foi o periódico em que foi publicada a ampla maioria dos títulos, seguida por O Hospital, Arquivos Brasilei ros de Endocrinologia e Metabologia, Revista Brasileira dePesquisas Médi cas eBiológicas e Arquivos Brasileiros de Nutrição.

Quanto às temáticas abordadas (Tabela 4), 13 (14,9\%) foram inseridos nos campos da endocrinologia e/ ou da fisiologia; 62 (71,3\%) da nutrição em saúde pública e/ ou tema de conteúdo social e 12 (13,8\%) da nutrição básica e experimental. Conseqüentemente, este foi o período de auge da temática nutrição em saúde pública dentro da trajetória intelectual de Chaves, sobremodo em função do tom de denúncia (crítica político-social) verificado nas suas matérias publicadas nos jornais. Um detal he que chama muito a atenção é que do total de 42 artigos de jornal, 40 (95,3\%) trazem uma abordagem no campo social e $37(88,0 \%)$ foram publicados entre 1964 a 1968, momento em que ainda havia uma certa liberdade de expressão dentro do contexto da ditadura militar.

$\mathrm{E}$, finalmente, neste período irão surgir os primeiros trabalhos abordando a questão das conseqüências biológicas e sociais da desnutrição protéico-calórica na população nordestina, sobretudo a questão do comprometimento físico e intelectual gerado pela carência de proteínas. Temática esta que irá garantir uma certa especificidade à obra de Chaves, associando-o à autoria da "teoria da geração de uma população de nanicos e deficientes mentais no Nordeste brasileiro". Enquanto desdobramento das pesquisas desenvolvidas nos campos da fisiologia e da nutrição experimental sobre o valor das proteínas na alimentação humana, ao longo do período em apreço, identificamos pelo menos 10 títulos que abordam a questão.

A monografia A Nutrição, o Cérebro ea Mente (Chaves, 1971), que tomamos como objeto de análise, é composta por dez seções: onde nas seis primeiras, com base em revisões bibliográficas, o autor apresenta breves considerações sobre a anatomia, a fisiologia e o metabolismo do encéfalo, destacando a importância da nutrição no delineamento da sua estrutura anatômica e funcional; as três últimas seções são dedicadas basicamente à discussão das conseqüências biológicas e econômico-sociais da des- nutrição, particularmente sobre o desenvolvimento intelectual infantil. Mas, ele não se limita a enxergar a desnutrição como um fator isolado no processo de determinação do desenvolvimento cerebral e da capacidade intelectual dos indivíduos. Assim sendo, em suas conclusões, ele também chama a atenção para a interação de outros fatores biológi cos e sociais envolvidos neste processo (Chaves, 1971).

No capítulo 7, intitulado A IdadeVulnerável e a Educação, observamos que há uma nítida preocupação do autor em apresentar um conjunto de argumentos técnico-científicos enfatizando a vulnerabilidade biológico-social infantil, com ênfase para o grupo etário de 1 a 4 anos de idade, e consequentemente buscando legitimidade para o programa de CERNs, modalidade de intervenção nutricional desenvolvida pelo INUFPE em alguns municípios da Zona da Mata-Sul de Pernambuco, ao longo do período de 1968/ 1972 (Batista Filho et al., 1970; Chaves, 1971).

Em relação aos estudos acerca dos efeitos produzidos pela desnutrição e outros fatores sobre o sistema nervoso das crianças assistidas pelos CERNs, Chaves (1971:73) relata, entre outros fatos, que foram observadas "el evadas incidências de alterações psi comotoras, sendo comum encontrar crianças de 2 e 3 anos de idade ainda engatinhando, falando muito pouco e apáticas". Relata ainda que ao saírem do quadro de desnutrição grave, "as crianças começam a se interessar pelo ambi ente que as cerca; brincam, jogam, correm, brigam, etc., atitudes peculiares da criança normal" (Chaves, 1971:75).

Observamos ao longo de A nutrição, o cérebro e a mente, sobremaneira na introdução e nos três últimos capítulos, que algumas passagens do texto podem perfeitamente ser concebidas como críticas bastante sutis, feitas por Chaves aos governos militares. Sutileza que apenas ganha sentido, quando nos reportamos ao contexto em que este livro foi produzido e editado. Diante do quadro de endurecimento da censura e da repressão policial-militar verificado nos anos 1968/1974, torna-se compreensível o abrandamento de al gumas passagens do texto, em que, a nosso ver, Chaves procura criticar o modelo de desenvolvimento econômico adotado pelos governos militares do pós-1964 (Chaves, 1971).

Quando nos reportamos ao contexto em que este livro foi editado, percebemos que estamos em pleno período do chamado milagre econômico brasileiro, época da construção de grandes obras como a Transamazônica, a ponte Rio-Niterói, etc. Época do discurso do "primeiro crescer, depois dividir", bastante eviden- 
ciado ao longo do governo do General Médici (1969/1973). Neste sentido, torna-se compreensível a metáfora contida no desfecho da apresentação de A Nutrição, o Cérebro ea Mente, feita por Emílio Giacomini (Chaves, 1971):

“É preciso plantar, é preciso colher, é preciso fabricar, é preciso transportar, é preciso enrique cer. Mas é preciso, antes de tudo, consumir. É preciso comer. É preciso viver. Nada sefaz, quando seéfaminto.

Não é com a fome das crianças que se constrói o futuro de qual quer nacionalidade".

Torna-se compreensível, também, o apelo humanista, lançado por Chaves, ao longo desta e de outras publicações deste período, a exemplo da afirmativa a seguir:

"O primeiro passo para combater a desnutrição e a pobreza é, sem dúvida, a modificação ética e moral do homem. Sem essa modificação, qualquer plano fracassará ea pobreza ea fome assumirão maiores proporções no ano 2000, apesar dos grandes avanços da Ciência eda Técnica" (Chaves, 1971:91).

\section{3/1982: a nutrição básica e aplicada}

Neste período em análise, verificamos o desenvolvimento das suas últimas atividades administrativas, quando Chaves assumiu a coordenação do Curso de Mestrado em Nutrição (07/ 1975 a 06/ 1976) e a chefia do Departamento de Nutrição da UFPE (09/ 1975 a 06/ 1976). Além disso, apontamos o ano de 1978 como o momento de ápice desta trajetória, quando, muito merecido, concederam-Ihe o título de Professor Emérito da UFPE.

Em relação à sua produção científica, observamos que, no período de 1973/ 1982, foram listados 56 títulos de sua autoria, o que representa $20,6 \%$ do total de 272 títulos arrolados. Em levantamento bibliográfico paralelo, identificamos mais um artigo de autoria deste autor que não se encontra listado em Costa (1995b) (Chaves, 1980).

Quanto ao critério autoria (Tabelas 1 e 2), 42 (75,0\%) são de autoria individual e, nos 14 de autoria coletiva, em 3 ele aparece como primeiro autor.

Quanto ao critério natureza do título (Tabela 3), identificamos três artigos publicados em periódicos internacionais; 14 em periódicos nacionais; dois em periódicos locais; dois em periódico do INUFPE e dois em Jornal; três livros; 17 capítulos de livros e 13 publicações em anais de eventos científicos. Por conseguinte, a modalidade de publicação de maior evidência foi o artigo em periódico especializado, totali- zando 39,3\% do total de títulos. Sendo a Revista Brasileira de Medicina e a Revista Brasileira de Pesquisas Médicas e Biológicas, os periódicos que concentraram a maioria destes títulos.

Quanto às temáticas abordadas (Tabela 4), $28(50,0 \%)$ títulos foram inseridos no campo da endocrinologia e/ ou fisiologia; 20 (35,7\%) na nutrição em saúde pública e/ ou tema de conteúdo social; e 8 (14,3\%) na nutrição básica e experimental. Verificamos que houve um certo retorno do professor aos temas da endocrinologia e/ ou fisiologia nutricional. No mesmo sentido, uma certa tentativa, em grande parte dos títulos, de realização de uma síntese entre a endocrinologia e/ ou fisiologia e a nutrição em saúde pública. Por outro lado, observa-se o esvaziamento da nutrição básica e experimental, a medida que o professor aparece como autor secundário nestes títulos. $\mathrm{E}$, finalmente, em 1978, com a publicação de Nutrição Básica e Aplicada (Chaves, 1978), encerrou-se, praticamente, aos 72 anos, a trajetória de produção intelectual de Chaves. Após, em 1981, aparece a publicação de um resumo em anais de congresso e, em 1982 e 1983, quatro publicações póstumas foram registradas (Chaves morreu, em 24 de maio de 1982, na cidade do Recife, aos 76 anos de idade).

Nutrição Básica e Aplicada, além de ser a publicação que popularizou Chaves, uma vez que tornou-se uma das principais referências bibliográficas do processo didático-pedagógico de formação do nutricionista brasileiro nos anos 1980, constituiu a obra síntese da trajetória acadêmico-intelectual deste autor.

Como o próprio título sugere, o livro apresenta-se estruturado em duas partes. A primeira delas, intitulada Nutrição Básica, é composta por dezesseis capítulos, dos quais doze são assinados por Chaves. Nesta primeira parte, que em termos quantitativos representa cerca de $70 \%$ do volume do livro, dentro de uma perspectiva essencialmente biológica, os 16 capítulos abordam, entre outros, conteúdos sobre a composição e o valor químico-fisiológico dos distintos nutrientes (hidratos de carbono, lipídeos, proteínas, vitaminas, minerais e água); sobre a determinação de requerimentos nutricionais dos diferentes grupos etários e sobre as relações entre a nutrição e o processo de crescimento e desenvolvimento do ser humano, o trabalho físico, o sistema nervoso central e a ecologia. Por outro lado, a segunda parte do livro, intitulada Nutrição Aplicada, é composta por seis capítulos. Em um destes capítulos, intitulado Principais Carências Nutricionais, Chaves assina as seções que abordam aspectos da fisiopatologia e da epidemiologia da desnutri- 
ção protéico-calórica (DPC) e do bócio endêmico. Nesta segunda parte, que conseqüentemente representa os $30 \%$ restantes do volume do livro, na tentativa de articulação das perspectivas biológica e social, estes seis capítulos abordam conteúdos temáticos que, em seu conjunto, vinculam-se ao campo da nutrição em saúde pública, tais como os métodos de diagnóstico do estado nutricional de populações; a epidemiologia das principais carências nutricionais no Brasil; o sinergismo entre nutrição e infecção; os determinantes econômico-sociais da desnutrição e os programas de intervenção nutricional.

Em Nutrição Básica e Aplicada, ao discutir os aspectos econômico-sociais da desnutrição, Chaves voltou a fazer referências aos dois principais clássicos de Castro - Geografia da Fome e Geopolítica da Fome--, referendando as concepções deste autor sobre a fome endêmica. Aliás, observamos que a visão ecológico-humanista com a qual Chaves aborda os conceitos de produção de alimentos, crescimento demográfico e desenvolvimento econômico-social, em muito aproxima-se ou identifica-se com as concepções defendidas por Castro. Acreditamos ainda que este resgate do conceito de fome endêmica e das referências às obras proibidas de Castro, que morreu no exílio político, em Paris, no ano de 1973, possa ter outros significados. Com ele, Chaves além de prestar uma homenagem póstuma ao seu conterrâneo cientista, rebelava-se contra as atrocidades cometidas pela ditadura militar e, simultaneamente, prenunciava o abrandamento da censura no campo acadêmico-científico e o início da abertura política no País.

Na seqüência do capítulo, ao apresentar uma visão um tanto catastrófica em relação às questões da produção de alimentos, do crescimento demográfico e do desenvolvimento econômico exclusivo, observamos uma certa aproximação deste autor com determinadas concepções neo-malthusianas, muito em voga nos anos 1970, em face das crises mundiais de alimentos, do petróleo e da degradação das condições de vida de significativas parcelas da população humana. E que, no caso específico do Brasil, evidenciou-se no pós-1974, como sintomas associados ao fim do milagre econômico, entre os quais a elevada prevalência de fomee desnutrição atestada pelo Estudo Nacional da Despesa Familiar (ENDEF). Entretanto, parecenos que ao final desta sua discussão, acaba prevalecendo uma visão ecológico-humanista dos processos de determinação e de combate à fome/ desnutrição endêmicas. Sendo assim, ele sintetiza:
“O objetivo final do desenvolvimento (...) deveser seguramente a mel horia do que conhecemos como qualidade de vida. E isto não pode ser al cançado somente através do crescimento econômico, especial mente medido pela renda per capita nacional. O progresso deveser humanizado; somente quando considera o ser humano o desenvol vimento pode ser ol hado de maneira mais ampla.

Vale ressaltar ainda que o desenvol vimento avaliado apenas pelo produto nacional bruto, sem abranger todas as camadas sociais, favorece somentea pequenos grupos e pouco influi no combateà desnutrição endêmica eà sua principal causa: a pobreza" (Chaves, 1978:326).

Nas considerações finais deste capítulo, ele acrescenta importantes elementos explicativos ao processo de determinação da fome endêmi$\mathrm{ca}$, garantindo assim uma maior consistência à sua visão ecológico-humanista. Neste sentido, suas críticas à "sociedade de consumo" e ao desenvolvimento tecnológico voltado exclusivamente para interesses econômicos, em detrimento da satisfação das necessidades básicas dos seres humanos, levam-no a estabelecer um prognóstico bastante pessimista para a fome endêmica mundial:

“Vivemos numa época dominada pela supertecnologia, visando à produção em massa para fins al tamente lucrativos, na qual a máquina compete com o homem e o esmaga. É uma característica da sociedade de consumo, que exige a utilização dos bens de consumo em benefício, sobretudo, dos grupos econômicos de mel hor nível, marginalizando, quase sempre, as comunidades como um todo. As estruturas eas infra-estruturas de sociedades deste tipo são incompatíveis com as necessidades e interesses das col etividades em geral. A fometenderá a aumentar, a não ser que o homem se modifique, tornando-semenos egoísta e mais comunitário, que as estruturas políticas se transformem evisem mais aos interesses das soci edades" (Chaves, 1978:327).

Assim sendo, na tentativa de evitar a confirmação deste prognóstico negativo, por meio do resgate de valores éticos, como a solidariedade humana, ele lança o apelo à adoção do paradigma humanista, de forma explícita:

"É preciso considerar o homem gl obalmente, com ampla visão humanista, esituá-lo em uma posição hierárquica realmente superior, mas entrel açado com os outros animais e o mundo vegetal, ou seja, em perfeita harmonia com o seu ambientefísico, único meio de utilizar-seda natureza, conservando-a, sem destruí-la.

Em face de sua posição hi erárquica no reino animal, todos os mei os devem ser racionalmen- 
te aplicados para evitar a deterioração do homem pela fome, pela ignorância, pela apatia e pela delinqüência, agentes estes que atuam si nergicamente no complexo da pobreza. A tecnocracia, a acel eração do desenvol vimento econômico exclusivo, sem consi derar os aspectos biológi cos esociais, acarretam mudanças bruscas, sem o tempo necessário para a adaptação, e colocam à margem os direi tos el ementares do ser humano" (Chaves, 1978:327).

Observa-se em algumas passagens dos trechos citados anteriormente, que apesar do sentido universal que o autor procura dar à sua abordagem, ela pode perfeitamente ser considerada como uma crítica particular ao caso brasileiro. Assim sendo, novamente apontamos as possíveis críticas que, sutilmente, Chaves procurava fazer à tecnocracia militar e ao seu modelo de desenvolvimento econômico, muito bem representado pelo milagre brasileiro. Por fim, ele aponta os limites do que chamamos de perspectiva biológica, como instrumento de abordagem dos processos de determinação e de combate à fome/ desnutrição endêmicas, indicando-nos a necessidade de adoção do que chamamos de perspectiva social, a qual, apesar de suas maiores amplitude e complexidade, poderia apresentar uma maior capacidade resolutiva para o problema da fome endêmica. Senão, vejamos:

"Percebemos, desse modo, que o problema da fome endêmi ca se desloca do plano científico, nutricional e médico para um campo muito mais amplo ecomplexo, de solução muito mais difícil: o econômico-social epolítico. Os programas assistenciais e preventivos em benefício dos grupos mais vulneráveis da população têm importância e são necessários. Mas somente atitudes políticas racionais e corajosas poderão, realmente, mudar o rumo dos acontecimentos e oferecer mel hores perspecti vas para a humanidade, que se debate numa das mai ores crises de sua história" (Chaves, 1978:327).

Podemos concluir que esta postura de deslocamento do problema da fome endêmica do plano científico, nutricional e médico para o campo econômico-social e político, apontada por Chaves em Nutrição Básica eAplicada, de certa forma, já estava sendo colocada em prática, desde agosto de 1974, quando um dos membros da sua equipe de trabalho do INUFPE, o Dr. Bertoldo Kruse Grande de Arruda, passou a assumir a presidência da agência central condutora da chamada Política Social de Alimentação e Nutrição do Estado Autoritário Brasileiro, o Instituto Nacional de Alimentação e Nutrição (INAN). No entanto, só a partir de 1976, com a instituição do II PRONAN, é que a con- cepção ecológico-humanista de "proteção aos grupos biológica e socialmente vulneráveis à desnutrição", defendida por Chaves e pelo conjunto de docentes do INUFPE, passou a ser o paradigma dominante do campo da nutrição no Brasil.

\section{Considerações finais}

A análise da trajetória acadêmico-intelectual de Chaves nos possibilitou a identificação de, pelo menos, quatro distintas fases de produção científica deste autor, ao longo do período 1932/ 1982. Fases demarcadas por distintos contextos vivenciados pela sociedade brasileira e, em particular, pela sociedade pernambucana, locus específico onde ocorreu todo o seu processo de criação científica. Ao longo destas cinco décadas investigadas, procuramos identificar os movimentos de continuidade e ruptura percorridos por este cientista em torno das duas principais vertentes conformadoras do campo da nutrição, a biológica e a social, e que deram passagem ao processo de gênese e consolidação da nutrição em saúde pública no Brasil (Vasconcelos, 1999a).

No primeiro recorte investigado (1932/ 1945), momento em que tiveram início os chamados processos de acumulação primitiva do capital simbólico (ou científico) e de construção do habitus científico deste autor (Bourdieu, 1994, 1998), observamos que a sua produção científica voltou-se exclusivamente ao campo da nutrição clínica, particularmente sobre aspectos fisiológicos e endocrinológicos individuais. Nos últimos anos deste período, sobretudo a partir de 1944, teve início o processo de publicação de artigos abordando conteúdos associados à chamada vertente social do campo da nutrição, que tinha Castro como um dos seus principais expoentes (Vasconcelos, 1999a). Tendência que se consolidaria, a partir de 1946, quando Chaves, em comunhão com outros cientistas da época, a exemplo de Castro e Gilberto Freyre, passou a reafirmar, embora cerca de uma década depois, a tese do aprimoramento eugênico do povo brasileiro mediante uma alimentação racional. Sendo assim, em alguns destes seus escritos ele passou a compartilhar da matriz ideológica que, à época, procurava desfocar da questão racial para a questão sócio-cultural, o preconceito racial/ climático que se tinha sobre o povo brasileiro, notadamente sobre o processo de mestiçagem no Brasil (Lima, 1997; Maio \& Santos, 1996; Marques, 1994; Stepan, 1996; Teixeira, 1997). Isto pode ser observado tanto em A Sub-alimentação no 
Nordeste Brasileiro (Chaves, 1948b), como em Alimentação e Saúde Pública (Chaves, 1948a).

Nos anos 1946/ 1963, observamos que o estudo das proteínas, sob o ponto de vista fisiológico, constituiu o paradigma central das investigações desenvolvidas por Chaves e seus assistentes. A importância desta temática, neste momento de sua trajetória intelectual, o faz apontar este período da história da nutrição como a "era das proteínas", que havia sido precedida, respectivamente, pelas "eras das vitaminase das calorias" (Chaves \& Teodósio, 1955: 523). Periodização esta que difere daquela apresentada por um outro nutrólogo da época (Costa, 1953), o qual identifica este período como uma "fase de interesse econômico-social" na história da nutrição, ainda que reconhecendo a continuidade da "fase de interesse fisiológico", que cronologicamente a havia precedido. Observamos ainda que, justamente nesta linha de investigação, reaparece o seu debate acadêmico com Castro, em torno do monopólio da competência científica do campo da nutrição (Bourdieu, 1994). No artigo anteriormente citado, ao apresentar o estado da arte sobre a questão das necessidades protéicas na nutrição humana, Chaves \& Teodósio (1955:532) referem uma série de investigações científicas que estariam em "desacordo com o ponto de vista de Josué de Castro, para quem a carência protéica aumenta[ria] a reprodução" humana. Provocação acadêmica relacionada à controvertida tese defendida por Castro em Geopolítica da Fome (Castro, 1951), para quem haveria uma associação entre consumo de proteínas e crescimento populacional, sendo a deficiência protéica um fator decisivo da explosão demográfica mundial (Barbosa Lima Sobrinho, 1982, apud Chaves, 1982; L'Abbate, 1982). Em relação às obras institucionais criadas, neste período em apreço, sob a direção de Chaves, quais sejam o INUFPE, o Curso de Nutricionistas e os Cursos de Especialização em Nutrição em Saúde Pública para médicos, acreditamos que seria interessante fazer um paralelo não apenas com as instituições criadas sob a orientação de Castro nos anos 1940 (o Instituto de Nutrição da Universidade do Brasil - INUB, o Curso de Nutricionistas e os Cursos para Nutrólogos desta instituição), mas com outras instituições semelhantes já existentes no Brasil e no exterior. Parece-nos que a partir da criação de tais instituições, Chaves procurava dotar o Estado de Pernambuco, ou mesmo o Nordeste, de um centro de ensino, pesquisa e extensão em nutrição, não apenas articulado e dependente, mas com plenas condições de competir com seus similares nacionais e internacionais. En- tretanto, num contexto marcado pelo ideário desenvolvimentista, em que a industrialização colocava-se como panacéia para solução da pobreza, da fome e das desigualdades regionais (Furtado, 1998), a criação de tais instituições extrapolam as fronteiras dos interesses pessoais do cientista Chaves, bem como as fronteiras de sua rivalidade acadêmica com Castro. Além da dinâmica interna do contexto local/regional, caracterizada sobretudo pelo movimento que podemos chamar de reinvenção do Nordeste, procuramos indicar que o processo de gênese da nutrição em saúde pública em Pernambuco ocorreu sob forte influência internacional, representada pela realização do Nutrition Survey do ICNND e por outras orientações de organizações internacionais, tais como OMS, OPAS, FAO e UNICEF.

Nos anos 1964/ 1972, o núcleo de pesquisadores do INUFPE, direcionado por Chaves, começou a realização das primeiras pesquisas e experiências de intervenção nutricional de caráter populacional na Zona da M ata pernambucana, caracterizando o processo de deslocamento do paradigma biológico para o social, que deu passagem à institucionalização do campo da nutrição em saúde pública no Estado de Pernambuco. Neste contexto, com o exílio de Castro (e de tantos outros que compunham a chamada elite político-pensante do Nordeste brasileiro e que, progressivamente, calaram-se, tornaram-se de direita ou foram expulsos do país pelos governos militares, tais como Celso Furtado, Francisco Julião e Paulo Freire), Chaves passou a ser o principal portavoz do campo da nutrição, tanto no enfoque biológico como no social. Neste sentido, quando analisamos a sua trajetória acadêmico-intelectual neste período, identificamos uma fase inicial situada nos anos 1964/ 1968, contexto de relativa liberdade de expressão dentro da ditadura militar, caracterizada sobretudo pela publicação de artigos em jornais, assumindo um certo tom de denúncia das condições de miséria e de fome existentes no Nordeste brasileiro, mormente em Pernambuco. Na segunda fase identificada, situada no período 1968/1972, com a mordaça da chamada linha dura da ditadura militar, particularmente sob os efeitos repressivos do Ato Institucional no 5 (Al-5) e do Decreto-Lei no 477 (Couto, 1998, 1999), observamos além da recorrência à temática biológica, a ausência ou o abrandamento das críticas sociais nas publicações deste autor.

Por fim, ao longo da análise do último recorte investigado (1973/1982), procuramos identificar como se tornou evidente o processo de movimentação das concepções de Chaves 
entre o biológico e o social, o técnico e o político, o regional e o universal. Foi neste movimento teórico-conceitual que identificamos uma maior aproximação deste cientista com as idéias de Castro. Outras evidências assinaladas precisam ser destacadas, mesmo que correndo o risco de estarmos com isso contribuindo para o processo de "mitificação" (Brito, 1995) deste cientista pernambucano. Como vimos, ao longo deste último recorte investigado, entre os seus 70 a 76 anos de idade, Chaves desenvolveu suas últimas atividades administrativas, assumindo tanto a chefia do Departamento de Nutrição como a coordenação do Curso de Mestrado; manteve-se na posição majoritária em relação à produção científica do seu grupo e publicou a obra síntese de sua trajetória, o clássico Nutrição Básica e Aplicada. Ao tomarmos esta obra como objeto de análise, assina-

\section{Agradecimentos}

Ao professor Dr. Ricardo Ventura Santos (Escola Nacional de Saúde Pública, Fundação Oswaldo Cruz), pelas orientações e críticas ao texto original. lamos que a mesma tornou-se uma das principais referências bibliográficas, conforme identificou Bosi (1988), do processo didático-pedagógico de formação do nutricionista brasileiro nos anos 1980. Revisando esta nossa constatação, acrescentaríamos que, além disso, Nutrição Básica e Aplicada se constituiu num dos principais veículos de circulação das idéias do grupo de cientistas do INUFPE, contribuindo para definir, pelo menos no período que analisamos, quais os problemas e os métodos legítimos do campo da nutrição em saúde pública no Brasil. Ou seja, a visão ecológico-humanista acerca dos métodos de diagnóstico, prevenção e tratamento do processo fome/ desnutrição, contida em Nutrição Básica e Aplicada, constituir-se-ia, a partir de então, no paradigma dominante da nutrição no Brasil, seja como ciência, política social e/ ou profissão.
Referências

ANDRADE, M. C., 1991. Secretaria da Fazenda: Um Século de História. Recife: Secretaria da Fazenda do Estado de Pernambuco.

AZEVÊDO, F. A., 1982. As Ligas Camponesas. Rio de Janeiro: Paz eTerra.

BATISTA FILHO, M., 1995. Nelson Chaves, o humanista. In: Quarenta Anos de Nutrição no Nordeste: Uma Retrospectiva (M. C. M. A. Costa, org.), pp. 74-80, Recife: Editora Universitária da Universidade Federal de Pernambuco.

BATISTA FILHO, M.; COÊLHO, H. A. L. \& BEGHIN, I. D., 1970. Centro de educação e recuperação nutricional. O Hospital, 77:425-450.

BOSI, M. L. M., 1988. A FaceOculta da Nutrição: Ciência eldeologia. Rio de Janeiro: Espaço eTempo/ Editora da Universidade Federal do Rio de Janeiro.

BOURDIEU, P., 1994. El campo científico. Revista de Estudios Sociales de la Ciencia, 1:131-160.

BOURDIEU, P., 1998. O Poder Simbólico. 2a Ed. Rio de Janeiro: Bertrand Brasil. 
BRITTO, N., 1995. Oswal do Cruz: A Construção de um Mito na Ciência Brasileira. Rio de Janeiro: Editora Fiocruz.

CASTRO, J., 1951. Geopolítica da Fome: Ensaio Sobre os Problemas de Alimentação e de População do Mundo. Rio de Janeiro: Livraria Editora da Casa do Estudante do Brasil.

CASTRO, J., 1980. Geografia da Fome (O Dilema Brasileiro: Pão ou Aço). 10a Ed. Rio de Janeiro: Antares/Achiamé.

CHAVES, N., 1948a. Alimentação e Saúde Pública: Mortalidade Infantil, Tuberculose, Estatura, Cárie Dentária. Recife: Imprensa Oficial.

CHAVES, N., 1948b. A Sub-Alimentação no Nordeste Brasileiro. Recife: Imprensa Oficial.

CHAVES, N., 1957a. A emoção e a vida moderna (parte I). Revista Brasileira de Medicina, 14:77-80.

CHAVES, N., 1957b. A emoção e a vida moderna (parte II). Revista Brasileira de Medicina, 14:161-165.

CHAVES, N., 1959a. Arterosclerose e nutrição (parte I). Revista Brasileira de Medicina, 16:632-640.

CHAVES, N., 1959b. Arterosclerose e nutrição (parte II). Revista Brasileira de Medicina, 16:712-724.

CHAVES, N., 1968. Sexo, Nutrição eVida. Recife: Imprensa Universitária.

CHAVES, N., 1971. A Nutrição, o Cérebro e a Mente. Rio de Janeiro: O Cruzeiro.

CHAVES, N., 1978. Nutrição Básica e Aplicada. Rio de Janeiro: Guanabara Koogan.

CHAVES, N., 1980. Novas estratégias para o combate à fome endêmica. In: Convenção Nacional de Nutrição e Dietética, Anais, pp. 145-152. Brasília: Associação de Nutricionistas do Distrito Federal.

CHAVES, N., 1982. Fome, Criança eVida. Recife: Fundação Joaquim Nabuco/ Editora Massangana.

CHAVES, N. \& TEODÓSIO, N. R., 1955. O mínimo e a média protéica na nutrição humana. Revista Brasileira de Medicina, 12:523-534.

COÊLHO, H. A. L., 1983. Formação do profissional nutricionista na América Latina e no Brasil, com ênfase em Pernambuco. Revista Alimentação \& Nutrição, 4:47-51.

COIMBRA, M.; MEIRA, J. F. P. \& STARLING, M. B. L., 1982. Comer eAprender: Uma História da Alimentação Escolar no Brasil. Belo Horizonte: Ministério da Educação e Cultura/Instituto Nacional de Assistência ao Estudante.

COSTA, D., 1953. A importância do ensino da nutrição: O seu desenvolvimento no Brasil. Revista Brasileira de Medicina, 10:645-650.

COSTA, D., 1954. O Socialismo: Conceito, Raízes Históricas, Posição Atual no Brasil. Rio de Janeiro: Organizações Simões.

COSTA, M. C. M. A., 1995a. Quarenta Anos de Nutrição no Nordeste: Uma Retrospectiva. Recife: Editora Universitária da Universidade Federal de Pernambuco.

COSTA, M. C. M. A., 1995b. Memória Científica do Departamento de Nutrição e das Instituições Predecessoras (1950-1966). Recife: Editora Universitária da Universidade Federal de Pernambuco.

COUTO, R. C., 1998. História Indiscreta da Ditadura e da Abertura - Brasil: 1964-1985. Rio de Janeiro: Record.

COUTO, R. C., 1999. Memória Viva do Regime Militar - Brasil: 1964-1985. Rio de Janeiro: Record.
FURTADO, C., 1997. Obra Autobiográfica de Celso Furtado. Rio de Janeiro: Paz eTerra.

FURTADO, C., 1998. O Capitalismo Global. São Paulo: Paz eTerra.

KELNER, S.; COUTINHO, A. D.; ROCHA, L. A.; COSTA, P. V.; ABATH, G. M. \& OLIVEIRA, A. C., 1985. História da Faculdade de Medicina do Recife 19151985. Recife: Centro de Ciências da Saúde, Universidade Federal de Pernambuco.

L'ABBATE, S., 1982. Fome e Desnutrição: Os Descaminhos da Política Social. Dissertação de Mestrado, São Paulo: Departamento de Ciências Sociais, Faculdade de Filosofia, Letras e Ciências Humanas, Universidade de São Paulo.

LAGO, E. S., 1995. Nelson Chaves, o pesquisador. In: Quarenta Anos de Nutrição no Nordeste: Uma Retrospectiva (M. C. M. A. Costa, org.), pp. 63-74, Recife: Editora Universitária da Universidade Federal de Pernambuco.

LIMA, E. S., 1997. Gênese e constituição da educação alimentar: A instauração da norma. História, Ciências, Saúde- Manguinhos, 5:57-83.

MAIO, M. C. \& SANTOS, R. V., 1996. Raça, Ciência e Sociedade. Rio de Janeiro: Editora Fiocruz/Centro Cultural Banco do Brasil.

MARQUES, V. R. B., 1994. A Medicalização da Raça: Médicos, Educadores e Discurso Eugênico. Campinas: Editora da Universidade Estadual de Campinas.

MONTEIRO, E. A. A., 1995. Nelson Chaves, o professor. In: Quarenta Anos de Nutri ção no Nordeste: Uma Retrospectiva (M. C. M. A. Costa, org.), pp. 58-63, Recife: Editora Universitária da Universidade Federal de Pernambuco.

SHANK, R. E., 1976. Nutrição em medicina preventiva. In: Medicina Preventiva (H. R. Leavell \& E. G. Clark, org.), pp. 182-226, São Paulo: McGraw-Hill do Brasil.

SOARES, A. J., 1982. A Frente do Recife e o Governo Arraes: Nacionalismo em Crise- 1955/1964. Rio de Janeiro: Paz eTerra.

STEPAN, N. L., 1996. The Hour of Eugenics: Race, Gender, and Nation in Latin America. New York: Cornell University Press.

TEIXEIRA, L. A., 1997. Da raça à doença em CasaGrande \& Senzala. História, Ciências, Saúde Manguinhos, 4: 231-243.

VASCONCELOS, F. A. G., 1990. Delimitação da prática profissional do nutricionista em saúde coletiva. Revista Alimentação \& Nutrição, 10:25-32.

VASCONCELOS, F. A. G., 1999a. Os Arquivos Brasileiros de Nutrição: Uma revisão sobre produção científica em nutrição no Brasil (1944 a 1968). Cadernos de SaúdePública, 15:303-316.

VASCONCELOS, F. A. G., 1999b. Como Nasceram os Meus Anjos Brancos: A Constituição do Campo da Nutrição em Saúde Pública em Pernambuco. Tese de Doutorado, Rio de Janeiro: Escola Nacional de Saúde Pública, Fundação Oswaldo Cruz.

YPIRANGA, L. \& GIL, M. F., 1989. Formação profissional do nutricionista: Por que mudar? In: II Se minário Nacional sobre o Ensino de Nutrição (D. T. O. Cunha, L. Ypiranga \& M. F. Gil, org.), pp. 2036, Goiânia: Federação Brasileira de Nutrição. 